\title{
Differences in the prevalence of overweight, obesity and underweight among children from primary schools in rural and urban areas
}

\author{
Katarzyna Wolnicka1,2, Mirosław Jarosz' ${ }^{1}$, Joanna Jaczewska-Schuetz ${ }^{1,2}$, \\ Anna Małgorzata Taraszewska, ${ }^{1,2}$ \\ ${ }^{1}$ Department of Nutrition and Dietetic with Clinic of Metabolic Diseases and Gastroenterology, National Food and \\ Nutrition Institute, Warsaw, Poland \\ ${ }^{2}$ Division of School Nutrition, National Food and Nutrition Institute, Warsaw, Poland \\ Wolnicka K, Jarosz M, Jaczewska-Schuetz J, Taraszewska AM. Differences in the prevalence of overweight, obesity and underweight among \\ children from primary schools in rural and urban areas. Ann Agric Environ Med. 2016; 23(2): 341-344. doi: 10.5604/12321966.1203902
}

\section{Abstract}

Introduction. Overweight adversely affects not only the health and development of children and adolescents but also their health in adulthood, increasing the risk of chronic non-communicable diseases and disabilities. The frequency of nutritional disorders among children and adolescents is increasing in many countries worldwide, including Poland.

Objective. To demonstrate differences in the nutritional well-being of school-age children depending on the school location: rural and urban areas.

Materials and methods. The study conducted in 2010 covered a total of 1,255 pupils, 627 girls and 628 boys, aged nine, from the area of five provinces of Poland: Pomorskie, Opolskie, Wielkopolskie, Podkarpackie and Masovian, representing the northern, southern, western, eastern and central regions of the country. Based on the height and weight measurements of children, the body mass index was calculated. The nutritional status was assessed according to the criteria of Cole et al. Results. The prevalence of overweight and obesity in girls and boys in separate regions of the country (villages, cities with less than 100,000 residents and cities with more than 100,000 residents) did not differ significantly.

Conclusions. The prevalence of overweight and obesity among children from rural and urban areas of Poland is similar. Analysis of regional differences in the prevalence of obesity, overweight and underweight among children and adolescents may indicate the direction of national and local activities aiming to reduce the inequalities resulting from nutritional wellbeing.

Key words

children, obesity, overweight, body mass index, rural and urban areas

\section{INTRODUCTION}

Obesity adversely affects not only the health and development of children and adolescents, but it also has a decisive impact on health in adulthood, increasing the risk of chronic noncommunicable diseases and disabilities. Underweight also entails some health consequences: it lowers immunity, decreases the general efficiency of the system and increases the risk of chronic diseases.

Nutritional well-being is influenced by many factors, including genetic and environmental, related to diet and physical activity, such as family, school and the environment of a young person - peers, fashion, advertisements, infrastructure, degree of urbanization, etc. There is also evidence that economic and social status have an impact on overweight and obesity among children and adults [1].

The frequency of nutritional disorders among children and adolescents increases in many countries around the world and in Europe [2]. The highest percentage of overweight children and young people is observed currently in the countries of southern and western Europe [3]. A dynamic increase in the number of obese and overweight children is also observed in developing countries [4].

Address for correspondence: Katarzyna Wolnicka, Department of Nutrition and Dietetic with Clinic of Metabolic Diseases and Gastroenterology, Division of School Nutrition, National Food and Nutrition Institute, Powsińska 61/63, 02-903 Warsaw, Poland

E-mail: kwolnick@izz.waw.pl

Received: 11 February 2014; accepted: 22 May 2014
In Poland, the nutritional status of children and young people is evaluated by many facilities and it usually pertains to selected groups or regions. Comparing this data in the context of differences between rural and urban areas is difficult because of the diversified evaluation criteria used to assess the nutritional well-being and the studies of different age groups. Results may be also influenced by the size of the cities covered by the research.

\section{OBJECTIVE}

The aim of the study was to evaluate the nutritional wellbeing of third-year pupils from randomly selected primary schools, taking into consideration the differences between rural and urban areas.

\section{MATERIALS AND METHOD}

Data were gathered in October 2010 within the evaluation of the programme 'School Fruit Scheme'. The study covered 38 primary schools selected from five provinces: Pomorskie, Opole, Wielkopolskie, Podkarpackie and Masovian, representing the northern, southern, central, eastern and western regions. The study was conducted with the approval of the Bioethical Commission at National Food and Nutrition Institute and after receiving the consent of 
all the participants' parents in writing. A stratified sampling was performed with a school as the basic unit of sampling. The lists of schools participating in the programme 'School Fruit Scheme' of 2010-2011, created by Agricultural Market Agency, and covered $71 \%$ of all primary schools in Poland, served as the basis for establishing the sampling framework. Before sampling, the schools were stratified into two areas: rural and urban. In each researched province, four schools from urban areas and three schools from rural areas were selected. In the second stage, sampling without replacement was performed, selecting two third-year groups from each school. In the event that two groups did not occur, another school was added. The study was designed in such a manner that a given group of pupils reflected the structure of the pupils' community learning in schools from urban and rural areas in Poland. The gender structure was representative of the country.

1,595 pupils aged nine were invited to participate in the programme - the number of pupils in the selected groups. Data of children who were present at school on the day of the study and who correctly filled out surveys, and whose parents had consented to the study, were analysed. The analysed group of 1,255 pupils - 627 girls and 628 boys - accounted for $78.7 \%$ of the group invited to participate in the study. In the examined group, $54.5 \%$ of the children were from schools in urban areas and $45.5 \%$ from schools in rural areas. The proportions between children learning in rural and urban districts in the examined group were similar to the demographic composition in Poland $-59.4 \%$ of pupils attended schools in urban areas and 40.6 schools in rural areas, according to data from the Central Statistical Office 2009-2010 for children born in 2001.

The anthropometric measurements - height and body mass - were performed by school nurses according to the standard, and the methodology of the screening test detecting physical development disorders. Height was measured with $0.5 \mathrm{~cm}$ accuracy in an upright standing position, without footwear. Body mass was measured by a verified and standardized scale with $100 \mathrm{~g}$ accuracy; children were weighed also without footwear and wearing light outer clothing. On the basis of the measurements of height and weight, the Body Mass Index (BMI) was calculated according to the applicable formula. Nutritional status was assessed according to the criteria of Cole et al. [5, 6]. Statistical analysis of the obtained data was performed by means of Statistica 7 software. For overweight, obesity, overweight and obesity jointly, and underweight, the odds ratio (OR) was calculated on the basis of the school location - village vs. cities with more than 100,000 residents).

Evaluation of the nutritional well-being was broken down according to the location of the schools: villages and towns with less than 100,000 residents, and cities with more than 100,000 residents.

The statistical characteristics of qualitative variables were presented as number and percentage distributions, and compared between the studied subgroups with the Pearson's chi-square test or the Fisher's exact test. Additionally, odds ratios (ORs) for the occurrence of various nutritional statuses among rural and urban dwellers were calculated, together with their 95\% confidence intervals $(95 \% \mathrm{CI})$.

\section{RESULTS}

The prevalence of overweight and obesity in girls and boys in separate regions of the country (village and cities with less than 100,000 residents, and cities with more than 100,000 residents) did not differ significantly. Among girls, overweight and obesity jointly occurred at a similar frequency in schools from rural areas and from bigger cities $(\mathrm{OR}=1.38$, $\mathrm{p}=0.18$; Tab. 1; Fig. 1). Similarly, data analysis did not confirm

Table 1. Nutritional statuses of girls in primary schools depending on school location

\begin{tabular}{|c|c|c|c|c|c|c|c|c|c|}
\hline \multirow[t]{2}{*}{ Girls } & \multicolumn{2}{|c|}{ Villages } & \multicolumn{2}{|c|}{$\begin{array}{c}\text { Cities } \\
\text { below } \\
100,000 \\
\text { residents } \\
\mathrm{N}=196\end{array}$} & \multicolumn{2}{|c|}{$\begin{array}{l}\text { Cities } \\
\text { above } \\
100,000 \\
\text { residents } \\
\mathrm{N}=158\end{array}$} & \multirow{2}{*}{$\mathrm{OR}^{*}$} & \multirow{2}{*}{$95 \% \mathrm{Cl}$} & \multirow{2}{*}{$p$} \\
\hline & $\mathrm{N}$ & $\%$ & $\mathrm{~N}$ & $\%$ & $\mathrm{~N}$ & $\%$ & & & \\
\hline Obesity & 11 & 4.0 & 9 & 4.6 & 6 & 3.8 & 1.06 & $0.39-2.93$ & 0.91 \\
\hline Overweight & 60 & 22.0 & 31 & 15.8 & 26 & 16.5 & 1.43 & $0.86-2.38$ & 0.17 \\
\hline Norm & 173 & 63.4 & 134 & 68.4 & 105 & 66.5 & 0.87 & $0.58-1.32$ & 0.52 \\
\hline Underweight & 29 & 10.6 & 22 & 11.2 & 21 & 13.3 & 1.32 & $0.72-2.41$ & 0.38 \\
\hline $\begin{array}{l}\text { Overweight } \\
\text { and obesity } \\
\text { together }\end{array}$ & 71 & 26.0 & 40 & 20.4 & 32 & 20.3 & 1.38 & $0.86-2.22$ & 0.18 \\
\hline
\end{tabular}

Prevalence of various nutritional statuses among rural and urban dwellers compared by Pearson's chi-square test or Fisher's exact test.

OR - odds ratio (villages vs. cities above 100,000 residents); $95 \% \mathrm{Cl}$ - $95 \%$ confidence interval; p-statistical significance.

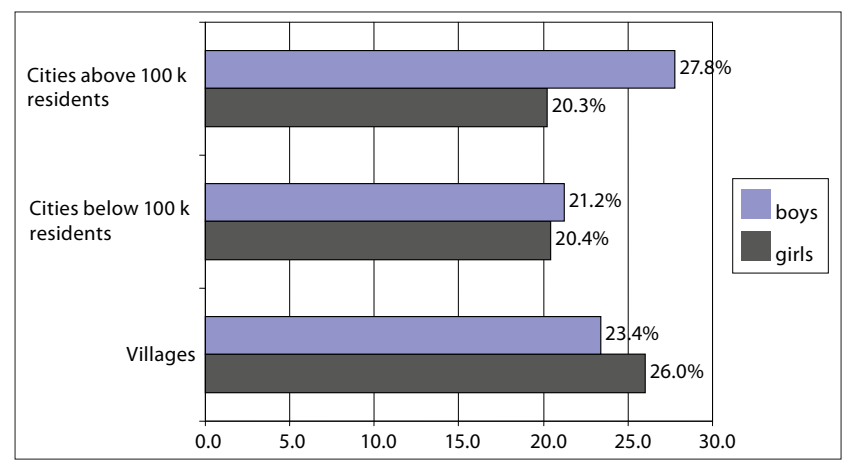

Figure 1. Comparison of the frequency of overweight and obesity together (\%) among boys and girls in primary schools depending on school location

Table 2. Nutritional status of boys in primary schools depending on school location

\begin{tabular}{|c|c|c|c|c|c|c|c|c|c|}
\hline \multirow[t]{3}{*}{ Boys } & \multicolumn{2}{|c|}{ Villages } & \multicolumn{2}{|c|}{$\begin{array}{l}\text { Cities } \\
\text { below } \\
100,000 \\
\text { residents }\end{array}$} & \multirow{2}{*}{\multicolumn{2}{|c|}{$\begin{array}{c}\text { Cities } \\
\text { above } \\
100,000 \\
\text { residents } \\
\mathrm{N}=144\end{array}$}} & \multirow{3}{*}{$\mathrm{OR}^{*}$} & \multirow{3}{*}{$95 \% \mathrm{Cl}$} & \multirow{3}{*}{$\mathrm{p}$} \\
\hline & & 291 & & & & & & & \\
\hline & $\mathrm{N}$ & $\%$ & $\mathrm{~N}$ & $\%$ & $\mathrm{~N}$ & $\%$ & & & \\
\hline Obesity & 19 & 6.5 & 12 & 6.2 & 10 & 6.9 & 0.94 & $0.42-2.07$ & 0.87 \\
\hline Overweight & 49 & 16.8 & 29 & 15.0 & 30 & 20.8 & 1.31 & $0.78-2.19$ & 0.30 \\
\hline Norm & 197 & 67.7 & 137 & 71.0 & 95 & 66.0 & 1.08 & $0.71-1.65$ & 0.72 \\
\hline Underweight & 26 & 8.9 & 15 & 7.8 & 9 & 6.3 & 1.47 & $0.67-3.23$ & 0.33 \\
\hline $\begin{array}{l}\text { Overweight } \\
\text { and obesity } \\
\text { together }\end{array}$ & 68 & 23.4 & 41 & 21.2 & 40 & 27.8 & 0.79 & $0.50-1.25$ & 0.32 \\
\hline
\end{tabular}


that overweight and obesity jointly occurred more often in boys learning in schools in urban areas, bigger cities with more than 100,000 residents, than in schools in rural areas $(\mathrm{OR}=0.79$, $\mathrm{p}=0.32$; Tab. 2; Fig.1).

\section{DISCUSSION}

In contrast to previous studies, no significant differences were demonstrated in the prevalence of overweight and obesity among children from the rural and urban regions of Poland. Nevertheless, both findings of the presented study and the results of previous research suggest that, similar to other countries, the number of overweight and obese children in Poland is bigger than the number of underweight children $[7,8]$.

The OLAF study conducted in 2007 by the Children's Memorial Health Institute in Warsaw, representative of the Polish population, among children and adolescents at the age of 7-18 showed that among children aged nine - the same age as children in the current study - obesity and overweight jointly concerned $22 \%$ of boys and $20.6 \%$ of girls [9], according to the criteria of the International Obesity Task Force (IOTF). In the discussed study, overweight and obesity jointly occurred in $23.7 \%$ of boys and $22.8 \%$ of girls. Therefore, the study may indicate that the frequency of overweight had increased by $2 \%$ in last three years in comparison to 2007, when the OLAF research within the group of 9-year-old children was started.

The results of OLAF concerning the nutritional well-being demonstrated that excessive body mass occurred more often in boys. Moreover, this study showed that excessive body mass was more common in bigger cities. Primary schools in urban areas had a lower frequency of normal body mass than primary schools in rural areas $(67.2 \%$ vs. $70.0 \%$; OR $=0.88$; $\mathrm{p}=0.005)$. In urban regions, both in primary schools and middle schools, boys constituted the group at risk regarding excessive body mass [10].

The report by the Institute of Mother and Child concerning Health Behaviour in School-aged Children (HBSC) of 20092010, demonstrated that in Poland obesity and overweight more often concern boys and are more common in bigger cities (17.9\% of girls and $25.4 \%$ of boys) [11]. An earlier study of HBSC among teenagers aged 15 showed a difference between the frequency of overweight and obesity among boys and girls. However, no differences between the frequency of the excessive body mass between the urban and rural regions were indicated. It was observed that underweight was more common among girls from urban areas, similar to the results of the current study [12]. The study by Szponar et al. pertaining to the nutritional well-being of children at the age of 1-18, evidenced that the joint percentage of overweight and obesity was higher among boys form urban areas than from rural areas, and in the case of girls - it was higher in rural areas than in urban areas [13].

The presented study indicates the impact of social and economic factors on the occurrence of overweight and obesity. The research by Grajda, whose aim was to compare the frequency of overweight, obesity and underweight among children and adolescents in different provinces in Poland, demonstrated significant differences in the frequency of overweight and obesity in the analysed regions, and determined the provinces with lower risk: Małopolskie,
Świętokrzyskie, Lublin and Podkarpackie, and with higher risk of overweight and obesity: the Masovian province [14]. In the latter province, the risk of overweight and obesity was shown to be the highest, and the GDP/cap. is the highest in Poland, exceeding the national average by $60 \%$, whereas Podkarpackie province, with a low risk of overweight and obesity, has the GDP/cap. below 70\% of the national average [15]. It cannot be excluded that the social and economic status of a family and of a region of residence may influence the frequency of overweight and obesity among children and adolescents in Poland.

Due et al. [1] analysed the frequency of overweight and obesity among children and adolescents at the ages of 11 , 13 and 15 in 34 European countries, including Poland, with regard to macro-economic factors. Significant differences were observed in the occurrence of overweight and obesity of young people in different countries - from 3.5\% in Lithuania up to $31.7 \%$ in boys in Malta. The occurrence of overweight was connected with the smaller wealth of families in 21 from 24 countries of Western Europe, and 5 from 10 countries of Central Europe. In countries like Croatia, Estonia and Latvia, excessive body mass occurred more often in pupils from more wealthy families, irrespective of gender. In Poland, Lithuania and Macedonia, excessive body mass was more common in boys from wealthier families and in the case of girls the excessive body mass was more common in less wealthy families. It was found that in countries with higher incomes, a lower economic and social status was connected to a higher frequency of overweight and obesity, whereas in countries with medium incomes, an opposite correlation was noted. The economic status of a country measured on the basis of GDP/cap. influenced the direction of the correlation between the frequency of the excessive body mass and the social and economic factors [1]. Drewnowski and Specter suggest that the low cost of high-energy food in the USA and the probable choice of such food by people with lower incomes, may influence the nutritional well-being [16]. Globalization related to, among others, the spread of the western lifestyle, concerns less wealthy countries more often. Women and girls may be more prone to those influences, which could explain the relationship indicated between lower economic status and the occurrence of the excessive body mass in girls in Poland, Lithuania and Macedonia covered by the research, which did not concern boys in those countries.

Economic changes connected, among others, with advancing computerization, increasing number of cars owned by households, expanding supermarkets and fast foods may favour the development of overweight and obesity in some regions.

In Poland, it seems that unfavourable changes in lifestyle, including those pertaining to dietary habits and physical activity, concern children from both rural and urban areas. The differences, if any, in the nutritional well-being between regions/provinces, and between girls and boys, may be justified by environmental factors, health-related behaviours of local communities, cultural influences, social and economic factors, and economic changes. This issue, however, needs to be researched further $[7,17,18]$. 


\section{CONCLUSIONS}

This study has shown that the prevalence of overweight and obesity among children from rural and urban areas of Poland is similar.

Nevertheless, analysis of the regional differences in the frequency of overweigh, obesity and underweight in children and young people, may indicate in which direction nationwide and local activities should be aimed to decrease the inequalities resulting from nutritional well-being. There exists a need for further research and continuous control of the nutritional well-being of children, taking into consideration analysis of the differences between rural and urban areas.

\section{REFERENCES}

1. Due P, Damsgaard MT, Rasmussen M, et al. Socioeconomic position, macroeconomic environment and overweight among adolescents in 35 countries. Int J Obes. 2009; 33(10): 1084-1093.

2. Wang Y, Lobstein T. Worldwide trends in childhood overweight and obesity. Int J Pediatr Obes. 2006; 1: 11-25.

3. Lobstein T, Frelut ML. Prevalence of overweight among children in Europe. Obes Rev 2003; 4(4): 195-200.

4. Monteiro CA, Conde WL, Lu B, et al. Obesity and inequities in health in the developing world. Int J Obes. 2004; 28:1181- 1186.

5. Cole TJ, Bellizzi M, Flegal KM, et al. Establishing a standard definition for child overweight and obesity worldwide: international survey. $\mathrm{Br}$ Med J. 2000; 320: 1240-1243.
6. Cole TJ, Flegal KM, Nicholls D, et al. Body mass index cut offs to define thinness in children and adolescents: international survey. BMJ. 2007; 335: 194-202.

7. Hawkins SS, Griths LJ, Cole TJ. Regional differences in overweight: an effect of people or place? Arch Dis Child. 2008; 93: 407-413.

8. Population. Size and structure by territorial division 2008. Central Statistical Office 2009: http://www.stat.gov.pl/gus/5840_1863_PLK_ HTML.htm

9. Kułaga Z, Litwin M, Tkaczyk M, et al. Polish 2010 growth references for school-aged children and adolescents. Eur J Pediatr. 2011; 170: 599-609.

10. Gurzkowska B, Grajda A, Kułaga Z, Napieralska E, Litwin M. Distribution of body mass index categories among Polish children and adolescents from rural and urban areas. Med Wieku Rozwoj. 2011 Jul-Sep;15 (3): 250-7.

11. Mazur J, Małkowska-Szkutnik A (red.) Wyniki badań HBSC 2010. Raport techniczny. IMiD, Warszawa 2011.

12. Oblacinska A, Kołoło H, Mazur J. Socio-economic determinants of physical development disorders among 15-year-olds in Poland. Med Wieku Rozwoj. 2008, XII, 2, 549-557.

13. Szponar L, Ołtarzewski M. Epidemiology of undernutrition in population of children and adolescents in Poland. Pediatria Współczesna. 2004, 6, 1, 13-17.

14. Grajda A, Kułaga Z, Gurzkowska B, et al. Regional differences in the prevalence of overweight, obesity and underweight among polish children and adolescents. Med Wieku Rozw. 2011; 15(3): 258-265.

15. GUS: http://www.stat.gov.pl/gus/5840_3594_PLK_HTML.htm

16. Drewnowski A, Specter SE. Poverty and obesity: the role of energy density and energy costs. Am J Clin Nutr. 2004; (79): 6-16.

17. Fraser LK, Edwards KL, The association between the geography of fast food outlets and childhood obesity rates in Leeds, UK. Health Place. 2010; 16(6):1124-1128.

18. Potestio ML, Patel AB, Powell CD, McNeil DA, et al. Is there an association between satial access to parks/green space and childhood overweight/obesity in Calgary, Canada? Int J Behav Nutr Phys Act. 2009; 20(6): 77. 